\title{
MARINA COLASANTI E AS TRÊS FASES DA LITERATURA DE AUTORIA FEMININA
}

Angela Simone Ronqui Oliva

\begin{abstract}
RESUMO: O presente artigo visa analisar três pequenos contos da escritora contemporânea Marina Colasanti: "Para que ninguém a quisesse", "Quando já não era mais necessário" e "Perdida estava a meta da morfose", todos extraídos da obra Contos de amor rasgados (1986). Nosso intuito é verificar que, na literatura de Colasanti, ao analisarmos as atitudes das protagonistas, nota-se a presença de características que remetem às três fases da literatura de autoria feminina, propostas pela crítica e ensaísta norte-americana Elaine Showalter (1986).
\end{abstract}

PALAVRAS-CHAVE: Marina Colasanti. Fases. Autoria feminina.

ABSTRACT: This article aims to analyze three short stories by the contemporary writer Marina Colasanti: "Para que ninguém a quisesse", "Quando já não era mais necessário" and "Perdida estava a meta da morfose", present in Contos de amor rasgados (1986). Our goal is to verify that, in the literature by Colasanti, when we analyze the attitudes of the main characters, we can notice the presence of the three phases of literature produced by women, proposed by the American critic and essayist Elaine Showalter (1986).

KEYWORDS: Marina Colasanti. Phases. Literature produced by women.

Marina Colasanti é escritora contemporânea conhecida, principalmente, por abordar questões sobre o universo feminino e por sua luta em defesa dos direitos das mulheres. Esta temática encontra-se, sobretudo, em seus ensaios, mas está presente também em sua produção literária, por meio de seus contos. A escritora ganhou destaque também por sua obra literária infanto-juvenil que, muitas vezes, remete ao mito, a lendas e ao maravilhoso mundo dos contos de fadas.

Colasanti produz, em alguns de seus contos, uma literatura que possui um caráter militante, que visa dar a voz a mulher e denunciar uma sociedade que, de certa maneira, ainda é machista e vê a mulher como um ser inferior. De acordo com Linda Hutcheon (1991): “As mulheres ajudaram a desenvolver a valorização [...] das margens e do excêntrico como uma saída com relação à problemática de poder dos centros e às oposições entre masculino e feminino" (1991, p.35). 
Entretanto, Colasanti (2011) afirma que não usa a literatura para fazer alarde ideológico, já que, quando quis fazê-lo, utilizou outros veículos, como os seus livros de ensaios, a imprensa, a televisão. Contudo, acredita que toda boa literatura é social e que, certamente, seus posicionamentos nas questões de gênero transparecem também em sua produção literária.

Os três contos selecionados para este estudo, presentes na obra Contos de amor rasgados (1986) possuem mulheres como protagonistas. Todas elas apresentam características que as aproximam de cada uma das três fases da literatura de autoria feminina propostas por Showalter (1986).

\section{AS FASES DA LITERATURA DE AUTORIA FEMININA}

Elaine Showalter (1986) investigou a literatura produzida por escritoras inglesas entre 1840 até cerca de 1960 e, segundo ela, todas as chamadas "subculturas" literárias passaram por três grandes fases:

First, there is a prolonged phase of imitation of the prevailing modes of the dominant tradition, and internalization of its standards of art and its views on social roles. Second, there is a phase of protest against these standards and values, and advocacy of minority rights and values, including a demand for autonomy. Finally, there is a phase of self-discovery, a turning inward freed from some of the dependency of opposition, a search for identity. An appropriate terminology for women writers is to call these stages, Feminine, Feminist and Female (SHOWALTER, 1986, p. 13). ${ }^{1}$

A primeira, chamada de fase feminina (feminine) é aquela em que as escritoras imitam os valores dominantes patriarcais vigentes na época; é a fase de "imitação e internalização" (ZOLIN, 2009, p. 330).

\footnotetext{
${ }^{1}$ Primeiro, há uma prolongada fase de imitação dos modos prevalecentes da tradição dominante, uma internalização de seus padrões de arte e suas visões dos papéis sociais. Segundo, há uma fase de protesto contra estes padrões e valores e defesa dos direitos e valores das minorias, incluindo a procura de autonomia. Finalmente, há uma fase de autodescoberta, desejo de libertação de algumas das dependências da oposição, uma busca pela identidade. Uma terminologia apropriada para as escritoras mulheres é chamar estes estágios de Feminina, Feminista e da Mulher. (Tradução própria).
} 
A fase de protesto ou rebelde, segundo Bonnici (2007), é a fase de ruptura, de denúncia dos moldes dominantes patriarcais e de defesa dos direitos das mulheres e das minorias e é chamada de feminista (feminist).

A terceira, a fase fêmea (female) ou "da mulher" é caracterizada pela autodescoberta e pela busca da identidade (ZOLIN, 2009, p. 330), em que as mulheres produzem uma literatura própria, autenticamente feminina, sem amarguras.

É importante ressaltar que as fases literárias propostas por Showalter (1986) não se excluem, podendo, assim, ser encontradas todas nas obras de uma mesma escritora, como é o caso da literatura de Marina Colasanti.

\subsection{SOB O SIGNO DA SUBMISSÃO E DO DOMÍNIO MASCULINO}

O primeiro conto analisado, Para que ninguém a quisesse (1986), aborda o ciúme, a autoridade masculina e o sentimento de posse que o marido tem em relação à esposa. Nele, há dois personagens: o homem e a mulher, apresentados em uma relação hierárquica, em que o homem é o dominador, detentor do poder e a mulher é a dominada, sempre submissa. Para que nenhum homem a olhasse, o que seria uma ameaça ao seu domínio, o esposo faz com que sua mulher passe por um processo de perda de seus atributos:

Porque os homens olhavam demais para a sua mulher, mandou que descesse a bainha dos vestidos e parasse de se pintar. Apesar disso, sua beleza chamava a atenção, e ele foi obrigado a exigir que eliminasse os decotes, jogasse fora os sapatos de saltos altos. Dos armários tirou as roupas de seda, das gavetas tirou todas as jóias. E vendo que, ainda assim, um ou outro olhar viril se acendia à passagem dela, pegou a tesoura e tosquiou-lhe os longos cabelos (COLASANTI, 1986, p. 111).

O homem trata sua esposa como seu "objeto", fazendo com ela o que quiser. Esse domínio é reforçado pelos verbos "mandou", "exigir", quando não é ele próprio que executa as ações: "tirou", "tosquiou-lhe", verbos esses que revelam a relação dominador/dominada, ou seja, todos os verbos, todas as ações estão destinados ao homem; é ele quem age o tempo todo, enquanto a mulher demonstra passividade e submissão. 
Para expressar a autoridade e o poder exercidos pelo marido, Colasanti escolhe com exatidão os verbos "mandar" e "exigir", muito diferente de "pedir", por exemplo. "Mandar" significa "dar ordens a, exigir de" e "exercer autoridade; dominar, governar" (Michaelis, 2011), assim como "exigir" significa "impor como obrigação ou dever" e "ordenar" (Michaelis, 2011). Com isso, o conto deixa claro que aí é o homem quem detém o poder e determina o destino de sua mulher.

Nota-se que o homem "foi obrigado a exigir" tudo isso da esposa, ou seja, isto foi "imposto a ele", ele foi "forçado" a agir desta maneira, provavelmente pela própria sociedade que possui valores machistas e patriarcais e que vê a mulher como um ser inferior, que não pode ter sua própria personalidade. Sua atitude autoritária é justificada pela própria cultura a qual ele está submetido.

Há uma gradação nas ações que este homem impõe à sua mulher. Primeiramente, a esposa teve que "descer a bainha dos vestidos" e "parar de se pintar". Contudo, "apesar disso", a beleza da mulher ainda chamava a atenção. Depois, proibiu "os decotes", "os sapatos de saltos altos", de usar "roupas de seda" e "jóias", até chegar ao ponto máximo da violência e dominação, e "tosquiar-lhe os cabelos".

Ao fazer tudo isso, o homem vai, aos poucos, atingindo a vaidade, a beleza da mulher e sua autoestima. Nota-se que todos os aparatos (maquiagem, roupas de seda, sapatos de salto alto, joias) remetem-nos à ideia contemporânea de "beleza feminina", ou seja, é usando-os que a personagem se sente bela. Essa mulher é toda construída por esses aparatos humanos valorizados pela nossa sociedade e que a fazem se sentir aparentemente bela. Contudo, continua a ser vista pelo marido, pela sociedade e até por ela mesma como inferior, pois não reage às "ordens" de seu esposo, aceitando-as com passividade.

A exigência para que ela "descesse a bainha dos vestidos" é uma forma de encobrir a figura feminina, já que o estar exposto é perigoso para o homem. A perda de "poder" era temida por ele, o homem se incomodava com o fato de que outros homens pudessem olhá-la e admirá-la: "E vendo que, ainda assim, um ou outro olhar viril se acendia à passagem dela, pegou a tesoura e tosquiou-lhe os longos cabelos" (COLASANTI, 1986, p. 111), ou seja, o marido, após tirar seus aparatos, tira da esposa a única coisa que realmente pertencia a ela, que lhe era natural: seus cabelos. 
Nota-se que "tosquiar" é diferente de cortar. De acordo com o Dicionário Houaiss (2009), "tosquiar" significa cortar rente "lã, pelo ou cabelo". Percebe-se que na própria definição do verbo há uma gradação (lã, pelo ou cabelo). Lã se refere a carneiros e ovelhas e pelo se refere a animais, de maneira geral. A ovelha é um animal dócil e passivo, símbolo do sacrifício, assim como a esposa; ou seja, há, por meio deste verbo, uma certa animalização da mulher, o que lhe confere uma inferioridade ainda maior, principalmente em relação a sua passividade.

Depois disto, "Agora podia viver descansado. Ninguém a olhava duas vezes, homem nenhum se interessava por ela. Esquiva como um gato, não mais atravessava praças. E evitava sair” (COLASANTI, 1986, p. 111). Sua aparência não mais chamava a atenção. Isso é reforçado pelos pronomes indefinidos "ninguém", "nenhum" e pelo advérbio "não", que dão a ideia de negação, de recusa total. A mulher torna-se "esquiva como um gato". Esta comparação inferioriza ainda mais a personagem, pois a assemelha novamente a um animal. Ela não tem mais atitudes humanas, tão intensa foi esta "anulação" de sua identidade.

Contudo, após a "transformação" da esposa, o homem não sentiu falta da companhia da mulher, de sua personalidade, de seu caráter, mas sim de sua beleza, isto é, não era o "interior" da esposa que importava para ele, e sim seu "exterior", sua aparência física que lhe despertava o desejo: "Uma fina saudade, porém, começou a alinhavar-se em seus dias. Não saudade da mulher. Mas do desejo inflamado que tivera por ela" (COLASANTI, 1986, p. 111). Entretanto, nota-se que a saudade não era muita, ela era "fina", isto é, "constituída de partículas muito pequenas ou delgadas" (Michaelis, 2011), o que reforça a ideia de que o homem não se importava com a esposa.

Realmente, como sugere o título do conto: Para que ninguém a quisesse, ninguém a quis mesmo, inclusive ele, o próprio marido, que não gostava de sua esposa, mas da beleza dela e, juntamente com esta beleza, a esposa também se vai, já que perde todas as características que as definia.

A esposa acabou ficando tão "esquiva" que foi "mimetizada" e comparada aos móveis da casa: "Tão esquiva se fez que ele foi deixando de ocupar-se dela, permitindo que fluísse em silêncio pelos cômodos, mimetizada com os móveis e as sombras" (COLASANTI, 1986, p. 111). "Esquivar" significa "evitar (pessoa ou coisa que nos ameaça ou desagrada)", "evitar a conversação ou o trato de alguém" e "escapar" 
(Michaelis, 2011). Já "mimetizar" significa "tomar os hábitos, colorido ou estrutura de outro organismo ou do ambiente" (Michaelis, 2011), ou seja, a mulher passa a ser como os objetos e a sombra, um ser inanimado sem imagem definida, já que ela perde sua vaidade e, consequentemente, os traços que definiam sua imagem. Ela apenas "flui em silêncio" pela casa, ou seja, "corre em estado líquido" (Michaelis, 2011), já que esta mulher não mais se mostra concreta, real, não "anda", apenas “flui”. Ela perde a matéria que a torna ser.

Após este processo de "transformação" da personagem, ela perde totalmente sua vaidade e não quer mais se arrumar, "nem pensava mais em agradar o marido", "Largou o tecido em uma gaveta, esqueceu o batom." (COLASANTI, 1986, p. 112). A "violência simbólica" 2 (BOURDIEU, 2010) da qual é vítima a impede de conseguir se "recuperar", de voltar a ter uma identidade. As ações que ela executa, "largou", "esqueceu", denotam abandono. De acordo com o Dicionário de Símbolos, "a rosa tornou-se símbolo do amor e mais ainda do dom do amor, do amor puro..." (CHEVALIER \& GHEERBRANT, 2009, p.789). Entretanto, a rosa dada pelo marido foi abandonada, esquecida sobre a cômoda: "E continuou andando pela casa de vestido de chita, enquanto a rosa desbotava sobre a cômoda" (COLASANTI, 1986, p. 112). O ciúme, o autoritarismo e a violência contra a esposa levam a personagem ao "sufocamento", e ela deixa de ser não apenas mulher, mas também humana.

Em sua obra E por falar em amor (1985), Colasanti também aborda a temática do ciúme masculino que “... nunca é visto como ridículo, mas sim como essencialmente dramático. Pois, ao ter ciúme, um homem está defendendo um direito sagrado de posse, não apenas do corpo alheio, mas de sua própria honra que naquele corpo habita" (1985, p.198).

A violência física é praticada pelo marido quando tosquiou os cabelos da esposa. Mas a violência "simbólica", que fere o psicológico e o emocional feminino faz-se presente intensamente, ao forçar a esposa a passar por um processo de transformação, anulando, desta forma, a sua identidade. E isso, com o consentimento da própria

\footnotetext{
${ }^{2}$ De acordo com Bourdieu (2010), violência simbólica é baseada na construção de crenças no processo de socialização, que induzem o indivíduo a se enxergar e a avaliar o mundo de acordo com critérios e padrões definidos pelos dominantes. No caso de nosso estudo, é o que acontece com as mulheres (dominadas) em relação aos homens (dominadores/dominantes).
} 
mulher, que não luta por essa não transformação e aceita com passividade e submissão a decisão do marido.

Este conto mostra uma protagonista passiva, submissa, violentada física e simbolicamente e conformada com a sua condição de inferioridade. Ela não reage ao domínio masculino, pelo contrário, o aceita passivamente sem lutar ou protestar por mudanças.

Nesse sentido, levando em consideração as atitudes desta personagem, podemos aproximar este conto à primeira fase da literatura de autoria feminina proposta por Showalter (1986), pois nela há uma duplicação dos valores patriarcais vigentes, em que o lugar primário sempre pertence ao homem e, às mulheres resta apenas a marginalidade.

\subsection{O DESEJO DE LUTAR CONTRA O DESTINO}

O pequeno conto Quando já não era mais necessário (1986), retrata o castigo que a mulher sofre quando ousa fugir do domínio masculino. Inicia-se com a esposa implorando pelos carinhos do marido: "Beije-me", pedia ela no amor, quantas vezes aos prantos, a boca entreaberta, sentindo a língua inchar entre dentes, de inútil desejo" (COLASANTI, 1986, p. 19). Realmente, o desejo dela era "inútil”, pois o marido nem se importava, ia “... logo penetrando, mais seguro no túnel das coxas do que no possível desabrigo da pálida pele possuída" (COLASANTI, 1986, p. 19), ou seja, a mulher só servia para satisfazê-lo sexualmente.

Nota-se que a mulher pedia "aos prantos", o que significa "pedir com lágrimas, suplicar humildemente" (Michaelis, 2011), o que marca o sofrimento e a condição humilde desta mulher, além de demonstrar a extrema necessidade que ela sentia de ter os beijos e carinhos do marido. E "quantas vezes" lhe pedia, o que demonstra que este seu ato era constante.

Triste com seu casamento e cansada de implorar pelos carinhos de seu esposo que sempre os negava, a mulher resolve abandonar o lar. Conforme Beauvoir, “... o drama do casamento não está no fato de que não assegura à mulher a felicidade que promete - não há seguro de felicidade - e sim no fato de que a mutila; obriga a 
mulher à repetição e à rotina." (1967, p. 243). Esta rotina de "frieza" por parte do marido é o que faz com que a mulher tome coragem de mudar sua vida.

Mão na maçaneta, hesitou porém. Toda a sua vida passada parecia estar naquela sala, chamando-a para um último olhar. E, lentamente, voltou a cabeça.

Sem grito ou suspiro, a começar pelos cabelos, transformou-se numa estátua de sal (COLASANTI, 1986, p. 19).

A mulher hesita um pouco, já que não é fácil abandonar "toda sua vida passada". Contudo, neste conto, diferente do anterior, ela acaba agindo. Entretanto, suas ações a levam à sua própria perdição.

Marina Colasanti retoma aqui a passagem da Bíblia Sagrada sobre a mulher de Ló, que se transforma em uma estátua de sal por não obedecer a Deus.

Relembrando a passagem bíblica: Deus resolveu destruir Sodoma e as cidades vizinhas, pois não achou quase nenhuma pessoa justa nelas. Naquele dia, Ló perdeu praticamente tudo. Os noivos de suas filhas não acreditaram nos anjos de Deus, e ficaram na cidade condenada. A mulher de Ló, em desobediência aos mensageiros de Deus, olhou para trás e se tornou uma estátua de sal (Gênesis 19:14-26).

Neste conto, podemos inferir que o marido é o senhor supremo, comparado a Deus e, a mulher, ao resolver abandoná-lo, é severamente castigada. O marido, em vez de se sentir triste por perder sua esposa, pela primeira vez, "jogou-se [...] a seus pés". "E com excitada devoção, começou a lambê-la". Agora sim a mulher seria adorada, pois transformara-se em algo "inofensivamente imóvel, tão lisa, e pura, e branca, delicada como se translúcida..." (COLASANTI, 1986, p.19), seria agora a mulher "ideal", eternamente passiva, não teria mais vontades ou desejos, não reclamaria de nada, nem ousaria abandonar seu "amo”. Barthes afirma que “... basta que, num lampejo, eu veja o outro sob a forma de um objeto inerte, como empalhado, para que eu transfira meu desejo, desse objeto anulado, para meu próprio desejo; é o meu desejo que desejo, e o ser amado nada mais é que seu agente (1994, p. 23).

Pela ousadia cometida, ou seja, por querer mudar seu destino, a mulher teve que pagar com sua própria vida, visto que o "transformar-se em estátua" metaforiza a morte da personagem. 
O ato de "lamber" a esposa pode ter um significado ambíguo: de um lado, um ato de adoração do marido pela estátua da mulher e, de outro, uma espécie de "inferiorização" e "animalização" dele, que a lambe como um bovino lambe o sal.

Agora, como afirma o título do conto, “já não era mais necessário” os carinhos do marido, ou o desejo de mudar de vida, visto que a mulher se torna estátua, um ser inanimado.

Nota-se, neste conto, que a protagonista possui atitudes de protesto em relação ao domínio masculino. Ela luta contra seu destino de ser sempre passiva, submissa e violentada, opondo-se aos valores dominantes patriarcais. Entretanto, apesar do desejo de libertação, ao final do enredo, ela não consegue realmente se livrar de seu infeliz destino.

Nesse sentido, analisando as atitudes desta personagem, podemos fazer uma aproximação deste conto com a segunda fase da literatura de autoria feminina proposta por Showalter (1986), visto que, nesta fase, a mulher se rebela, luta, mas não consegue

sair: continua presa na teia patriarcal dominante. É, como afirma Xavier (1999) “... o beco sem saída".

\subsection{A CONQUISTA DA LIBERDADE E DA INDEPENDÊNCIA}

Acostumamo-nos a encontrar nos enredos dos contos de fadas tradicionais mulheres/princesas extremamente frágeis, passivas e submissas, que sofrem com as adversidades da vida e não conseguem superá-las sozinhas. Consequentemente, nos deparamos também com a figura do homem, geralmente representado pelo príncipe encantado, sempre forte, bondoso, belo e corajoso, ou seja, sempre representado com características positivas, e disposto a defender e/ou salvar a pobre moça indefesa dos perigos.

De acordo com Müller, "O herói representa o modelo do homem criativo, que tem coragem para ser fiel a si mesmo, aos seus desejos, as suas fantasias e as suas próprias concepções de valor. Ele se atreve a viver a vida, ao invés de fugir dela" (1987, p. 9).

Durante séculos, a figura do herói na literatura foi sempre representada pelo homem. Ele enfrenta os perigos com coragem e determinação. Já as mulheres dos 
contos de fadas tradicionais sempre foram vistas como passivas e submissas, não são nada independentes, e a realização de uma vida feliz está obrigatoriamente associada à sua união com o homem/príncipe encantado.

Contudo, a escritora contemporânea Marina Colasanti, em seu pequeno conto Perdida estava a meta da morfose (1986), desconstrói a figura do homem/príncipe encantado que há tanto tempo havia sido exaltado na literatura, e, em seu lugar, coloca um animal, um sapo asqueroso, que se relaciona com a protagonista, sobre o qual a mulher exerce pleno domínio. Em relação à desconstrução, Culler afirma que:

Desconstruir uma oposição é mostrar que ela não é natural e nem inevitável mas uma construção, produzida por discursos que se apoiam nela, e mostrar que ela é uma construção num trabalho de desconstrução que busca desmantelá-la e reinscrevê-la - isto é, não destruí-la mas dar-lhe uma estrutura e funcionamento diferentes (1999, p.122).

O conto faz uma paródia do tradicional A princesa e o sapo ou $O$ rei sapo, conto que possui várias versões. Neste clássico, seguindo a versão dos irmãos Grimm (2001), a princesa, ao brincar no jardim, deixa sua bola de ouro cair no lago e, para resgatá-la, recorre à ajuda de um sapo. $\mathrm{O}$ mesmo aceita devolver a bola à princesa, desde que ela dormisse com ele. A princesa aceita a proposta, mas, ao ter sua bola novamente, ela sai correndo para o castelo. Entretanto, o sapo não desistiu. Perseguiu a princesa e cobrou a promessa dela ao rei. Pressionada pelo pai, ela resolve cumprir sua palavra e, ao acordar na terceira noite em que dormira com o sapo, o mesmo se transforma em um belo príncipe, que lhe contou que uma bruxa havia lhe transformado no asqueroso anfíbio. Os dois se casaram e viveram felizes para sempre.

De acordo com Bettelheim, a história deste conto

... mostra que não podemos esperar que nossos primeiros contatos eróticos sejam agradáveis, pois são demasiado difíceis e repletos de angústia. Mas, se continuarmos, apesar da repugnância temporária, a permitir que o outro se torne cada vez mais íntimo, então num determinado momento experimentaremos um choque feliz de reconhecimento quando a proximidade total revelar a verdadeira beleza da sexualidade (2007, p. 389). 
$\mathrm{Na}$ versão clássica, a "verdadeira beleza" é revelada por meio da metamorfose (de sapo para homem) que ocorre, e faz com que o conto tenha aspecto positivo e tradicional, isto é, o final feliz geralmente esperado pelo leitor.

No conto de Colasanti, a protagonista ouve o coaxar de um sapo em seu jardim e resolve descer para procurá-lo. A descrição do animal nos dá a ideia de um ser asqueroso e feio, de “... corpo desgracioso sobre pernas tortas, gordo e verde, os olhos saltados, aguados como se chorando, o papo inchado debaixo da grande boca triste. Que criatura era aquela, repugnante e indefesa, que com tanto desejo a chamava?" (COLASANTI, 1986, p. 43). Conforme o Dicionário de Símbolos, "o medo desse animal crepuscular faz dele comumente, entre nós, um símbolo de fealdade e de falta de jeito" (CHEVALIER \& GHEERBRANT, 2009, p.803).

Entretanto, mesmo achando-o tão feio, a moça resolve colocá-lo em sua camisola e levá-lo até seu quarto, o que demonstra que ela não estava se importando com sua aparência, atitude que, de certo modo, "foge" do tradicional. E "naquela noite o sapo não coaxou. Suspirou a moça, descobrindo as viscosas doçuras do abismo" (COLASANTI, 1986, p. 43). Com o sapo, a moça satisfaz seus desejos. Ela o usa em benefício de seu prazer. Isso representa uma libertação do corpo feminino, um fim ao tabu da sexualidade da mulher que, por muito tempo, foi tratada de forma impura, pecaminosa, enquanto que a do homem era vista como algo normal. Segundo Góis “... somos educadas por mulheres, numa sociedade onde a virilidade e o prestígio do macho estão longe de serem apagados" (1991, p. 119). Entretanto, por meio da atitude desta protagonista, percebe-se claramente que a "virilidade" e o "prestígio" masculino desaparecem.

Assim como no conto tradicional, ao amanhecer, o sapo se transforma em homem, para a infelicidade da protagonista, que, cansada de tantos homens belos, deixa claro que preferia o sapo. O moço era "bonito, porém semelhante a tantos outros rapazes morenos e louros que haviam passado antes por aquela cama, sem jamais conseguir fazê-la estremecer" (COLASANTI, 1986, p. 43).

... no conto de Colasanti, o desencantamento é justamente a função desencadeadora do final decepcionante, tanto para a personagem como para o leitor. Ambos se desiludirão, pois a narrativa não apresenta solução, nem para a necessidade da moça de encontrar um amor verdadeiro, nem para o leitor que espera encontrar um final no qual tudo se harmonize (CARDOSO \& DUNGUE, 2011, p. 02). 
Aqui, a metamorfose, diferentemente da versão clássica, possui um sentido negativo, visto que é ela que frustra a protagonista. "Ao ganhar forma humana, o sapo perde seu charme, empobrece o imaginário da moça, esvazia o signo que a personagem poderia encantar e reencantar ao sabor do seu desejo" (CARDOSO \& DUNGUE, 2011, p. 6).

O próprio título do conto: "Perdida estava a meta da morfose" sugere que o objetivo da mudança, da transformação foi perdido em relação à versão tradicional, visto que, aqui, a protagonista não desejava esta mudança. Foi o sapo que a satisfez, e não o homem.

Neste pequeno conto, a inferioridade feminina desaparece completamente e a protagonista se livra realmente do domínio masculino. Por isso, podemos aproximar o conto da terceira fase da literatura de autoria feminina, chamada por Showalter (1986) de fase "fêmea", ou, como preferimos, a fase "da mulher", em que há a busca de uma identidade, uma autodescoberta, caracterizada pela “... construção de uma nova identidade liberta do peso da tradição" (XAVIER, 1999, p. 06). Surge, então, uma mulher dona de seu destino, totalmente livre das amarras que a sociedade machista patriarcal lhe impôs durante séculos.

\section{CONCLUSÃO}

Ao analisarmos as protagonistas (sempre mulheres) dos contos selecionados, podemos associar suas atitudes às fases da literatura de autoria feminina, propostas por Showalter (1986): a primeira, chamada de "feminine" (feminina) é a fase de imitação dos padrões dominantes patriarcais; a segunda, "feminist" (feminista), fase de protesto e defesa das minorias, e, a terceira, "female" (fêmea ou “da mulher"), em que há a busca de identidade própria.

Para que ninguém a quisesse apresenta uma protagonista que não luta contra seu infeliz destino, sempre passiva e submissa ao domínio do marido. Essa atitude da protagonista pode ser aproximada da fase que Showalter (1986) chama de feminina, em que “... tudo é construído de acordo com a mais estrita ideologia patriarcal, em que a mulher não tem voz, nem vez...” (ZOLIN, 2009, p. 331). 
Em Quando já não era mais necessário é possível perceber uma atitude próxima da chamada fase Feminista (Feminist), pois a história traz “... à tona as diferenças sociais cristalizadas entre os sexos, as quais cerceiam quaisquer possibilidades de a mulher atingir sua plenitude existencial" (ZOLIN, 2009, p. 331). No entanto, mesmo não conseguindo a "plenitude existencial", a protagonista tenta, luta pelos seus anseios, opondo-se ao domínio masculino.

Finalmente, em Perdida estava a meta da morfose se aproxima da terceira fase, descrita por Showalter (1986) como "female" (“da mulher"), já que, neste conto, Colasanti nos revela uma personagem decidida e moderna, que pensa em sua satisfação sexual e encontra-se bem longe das "amarras" machistas/patriarcais, mudando, desta forma, seu tradicional destino de "princesa" frágil, passiva e submissa. É a libertação total da mulher, que tem suas próprias vontades e age como bem quiser.

\section{REFERÊNCIAS:}

A princesa e o sapo. Disponível em : <http://www.historiasinfantis.eu/a-princesa-e-osapo/>. Acesso em 30 de janeiro de 2012.

BARTHES, Roland. Fragmentos de um discurso amoroso. Rio de Janeiro: Francisco Alves, 1994.

BEAUVOIR, Simone de. O segundo sexo: II a experiência vivida. Trad. Sérgio Milliet. 2. ed. São Paulo: Difusão Européia do Livro, 1967.

BETTELHEIM, Bruno. A psicanálise dos contos de fadas. Trad. Arlene Caetano. São Paulo : Paz e Terra, 2007.

BONNICI, Thomas. Teoria e crítica literária feminista: conceitos e tendências. Maringá: EDUEM, 2007.

BOURDIEU, Pierre. A dominação masculina. Trad. Maria Helena Kühner. 7 ed. Rio de Janeiro: Bertrand Brasil, 2010.

CARDOSO, Ronnie Francisco \& DUNGUE, Cléber Luís. O sapo, a moça e o texto desencantados. In : Revista Fronteira Z, São Paulo, n. 6, abril de 2011.

CHEVALIER, Jean \& GHEERBRANT, Alain. Dicionário de símbolos: mitos, sonhos, costumes, gestos, formas, figuras, cores, números. 24 ed. Rio de Janeiro: José Oylmpio, 2009. 
COLASANTI, Marina. Contos de amor rasgados. Rio de Janeiro: Rocco, 1986. E por falar em amor. 6 ed. Rio de Janeiro: Rocco, 1985.

e-mail. . Entrevista concedida a Angela Simone Ronqui Oliva em março de 2011 por

CULLER, Jonathan. Sobre a Desconstrução: teoria e crítica do pós-estruturalismo. Trad. Patrícia Burrowes. Rio de Janeiro: Record; Rosa dos Tempos, 1997.

GÊNESIS, 19:14-26. A justiça de Deus. In: BÍBLIA SAGRADA: Edição Pastoral. Trad. Ivo Storniolo. São Paulo: Editora Paulus, 1990.

GÓIS, M.M.S. Aspectos históricos e sociais da anticoncepção. Reproduo, v. 6, n. 3, p. 119-24, 1991.

GRIMM, Jacob \& GRIMM, Wilhelm. Contos de fadas. Trad. Celso M. Pacionik. São Paulo: Iluminuras, 2001.

HOUAISS Dicionário da Língua Portuguesa. Antônio Houaiss, Mauro de Salles Villar, Francisco Manoel de Mello Franco. Objetiva: Rio de Janeiro, 2009.

HUTCHEON, Linda. Teorizando o pós-moderno: rumo a uma poética. In: Poética do pós-modernismo. Trad. Ricardo Cruz. Rio de Janeiro: Imago, 1991.

MICHAELIS Dicionário da Língua Portuguesa. Disponível em: $<$ http://michaelis.uol.com.br/moderno/portugues/index.php $>$. Acesso em 02 de fevereiro de 2012.

MULLER, Lutz. O herói: todos nascemos para ser heróis. São Paulo: Cultrix, 1987.

RAMALHO, Christina. Mulheres, Princesas e Fadas: A hora da Desconstrução. In: Gênero. Niterói, v.1, n.2, p.41-48, 1. Sem. 2001.

SHOWALTER, Elaine. A Literature of Their Own. In: EAGLETON, M. Feminist literary theory: a reader. Cambridge, Mass.: Blackwell, 1986.

XAVIER, Elódia. Narrativa de autoria feminina na literatura brasileira: as marcas da trajetória. In: Mulheres e Literatura, v.3, 1999. Disponível em: <http://www.letras.ufrj.br/litcult/revista_mulheres/VOLUME3/31_elodia.html>. Acesso em 23 de agosto de 2010.

ZOLIN, Lúcia Osana. Crítica Feminista. In: BONNICI, Thomas e ZOLIN, Lúcia Osana (Orgs.). Teoria Literária. 3 ed. Ver. Ampl. Maringá: EDUEM, 2009.

Literatura de Autoria Feminina. In: BONNICI, Thomas e ZOLIN, Lúcia Osana (Orgs.). Teoria Literária. 3 ed. Ver. Ampl. Maringá: EDUEM, 2009.

RECEBIDO EM: 07 de maio de 2012

APROVADO EM: 05 de junho de 2012 